Supporting Information

\title{
Synthesis, Characterization, and Catalytic Activity of Bimetallic Ti/Cr Complexes
}

Jiawei Chen, Hunter B. Vibbert, Chengbo Yao, Amymarie K. Bartholomew, Alexander P. Aydt, Steffen Jockusch, Jack R. Norton, * Matthew Hammond, Michael Rauch

Department of Chemistry, Columbia University, 3000 Broadway, New York, New York 10027, United States

Table of Contents:

General Methods

Materials

S2

Figures

Table

S10

Computational Methods

S11

References

S11 


\section{General Methods}

Unless otherwise noted, all manipulations were carried out in an inert atmosphere box $\left(\mathrm{O}_{2}<1\right.$ ppm) or under Ar by standard Schlenk techniques. Glassware was flame or oven-dried immediately prior to use. NMR spectra were recorded on a Bruker 400 or $500 \mathrm{MHz}$ instrument. ${ }^{1} \mathrm{H}$ and ${ }^{13} \mathrm{C}$ NMR spectra are included in the Supporting Information as further support of the characterization data presented in the Experiment Section. ATR-FTIR data was collected on Bruker Alpha II FTIR instrument. Solution samples for electronic spectroscopy were prepared under argon. Absorption spectra were recorded on a Cary $60 \mathrm{UV}$-vis. Absorption maxima were obtained by spectral deconvolution using Igor64. Elemental analysis was carried out at Midwest Microlab. EPR spectra were recorded on a Bruker EMX spectrometer at ambient temperature in deoxygenated acetonitrile and deuterated benzene solution in a $3 \mathrm{~mm}$ (inner diameter) quartz tube. EPR simulations were performed with Bruker's EasySpin software. Magnetic susceptibility measurements were performed using a Cryogenics S700X SQUID magnetometer. Loose polycrystalline sample was placed into a gel capsule and secured in place with eicosane, which was placed inside a plastic straw. Magnetization data at $100 \mathrm{~K}$ from 0 to $7 \mathrm{~T}$ was used as a ferromagnetic-free purity test. Direct current $(\mathrm{dc})$ variable temperature magnetic susceptibility measurements were collected in the temperature range 3-295 K under an applied field of $0.1 \mathrm{~T}$. The magnetism data were corrected for the small diamagnetic contribution of the gel capsule containing the sample and the straw and the diamagnetic contribution of the compounds. Magnetic susceptibility data was modeled in PHI. ${ }^{1}$

X-ray diffraction data were collected on a Bruker Apex II diffractometer. Crystal data, data collection, and refinement parameters are summarized in the Supporting Information. The structures were solved using direct methods and standard difference map techniques and were refined by full-matrix least-squares procedures on $F^{2}$ with SHELXTL (version 2014/7). ${ }^{2-4}$ Crystallographic data for the structures have been deposited with the Cambridge Crystallographic Data Center as supplementary publications (CCDC 2032789-2032791). These data can be obtained free of charge from The Cambridge Crystallographic Data Centre via www.ccdc.cam.ac.uk/data_request/cif.

\section{Materials}

Tetrahydrofuran and benzene were distilled from sodium/benzophenone ketyl under Ar. Pentane was stirred over sulfuric acid for several days to remove any olefins and then was distilled from sodium under Ar. Toluene was purified by the method of Grubbs. ${ }^{5}$ Deuterated solvents (Cambridge Isotopes) were purified by vacuum transfer from the appropriate drying agent (potassium metal for benzene- $d_{6}$ and toluene- $d_{8}$, and $\mathrm{P}_{4} \mathrm{O}_{10}$ for acetonitrile- $d_{3}$ ). Bis(trimethylsilyl)acetylene (BTMSA) was purchased from Sigma-Aldrich Co. and used as received. $\mathrm{Cp}_{2} \mathrm{TiCl}_{2}$ and $\mathrm{Cp}_{2}{ }_{2} \mathrm{TiCl}_{2}$ were obtained as a gift from Boulder Scientific Co. and used as received. $\mathrm{Cp}_{2} \mathrm{Ti}(\mathrm{BTMSA}), \mathrm{Cp}^{*}{ }_{2} \mathrm{Ti}(\mathrm{BTMSA}),{ }^{6-7} \mathrm{Cp}^{*}\left(\mathrm{C}_{5} \mathrm{Me}_{4} \mathrm{CH}_{2}\right) \mathrm{TiCH}_{3},{ }^{8}$ and $\mathrm{CpCr}(\mathrm{CO})_{3} \mathrm{H}^{9-12}$ were prepared by literature methods. 


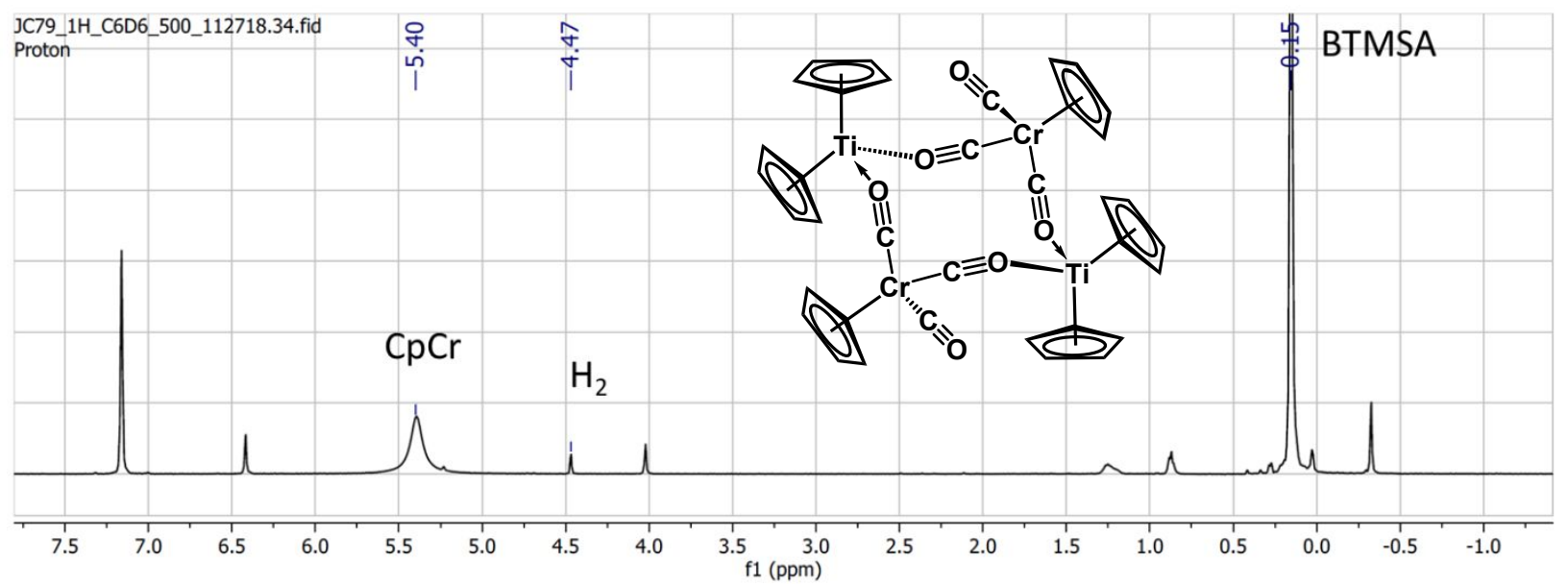

Figure S1. ${ }^{1} \mathrm{H}$ NMR $\left(\mathrm{C}_{6} \mathrm{D}_{6}\right)$ spectrum of reaction of $\mathrm{Cp}_{2} \mathrm{Ti}(\mathrm{BTMSA})_{2}$ and $\mathrm{CpCr}(\mathrm{CO})_{3} \mathrm{H}$.

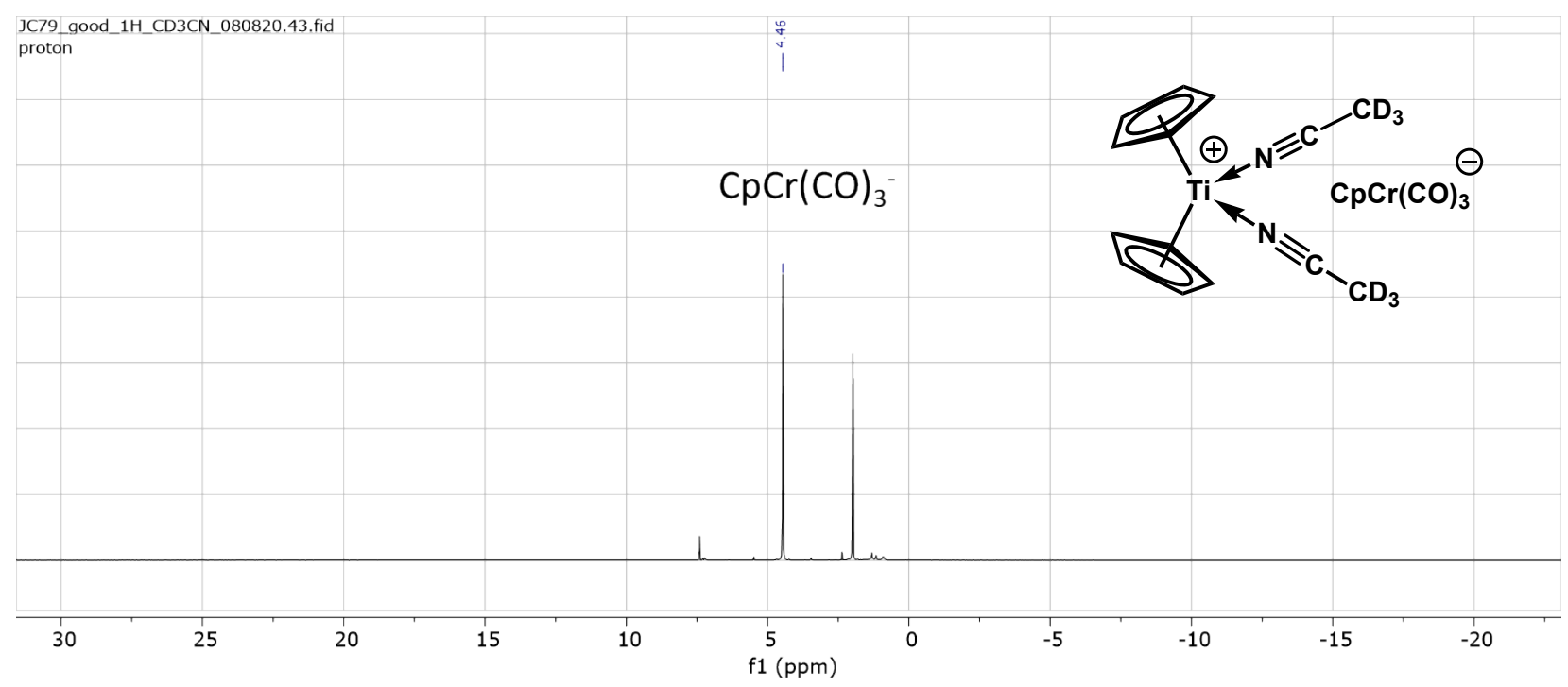

Figure S2. ${ }^{1} \mathrm{H}$ NMR $\left(\mathrm{CD}_{3} \mathrm{CN}\right)$ spectrum of $\mathbf{1}$. 


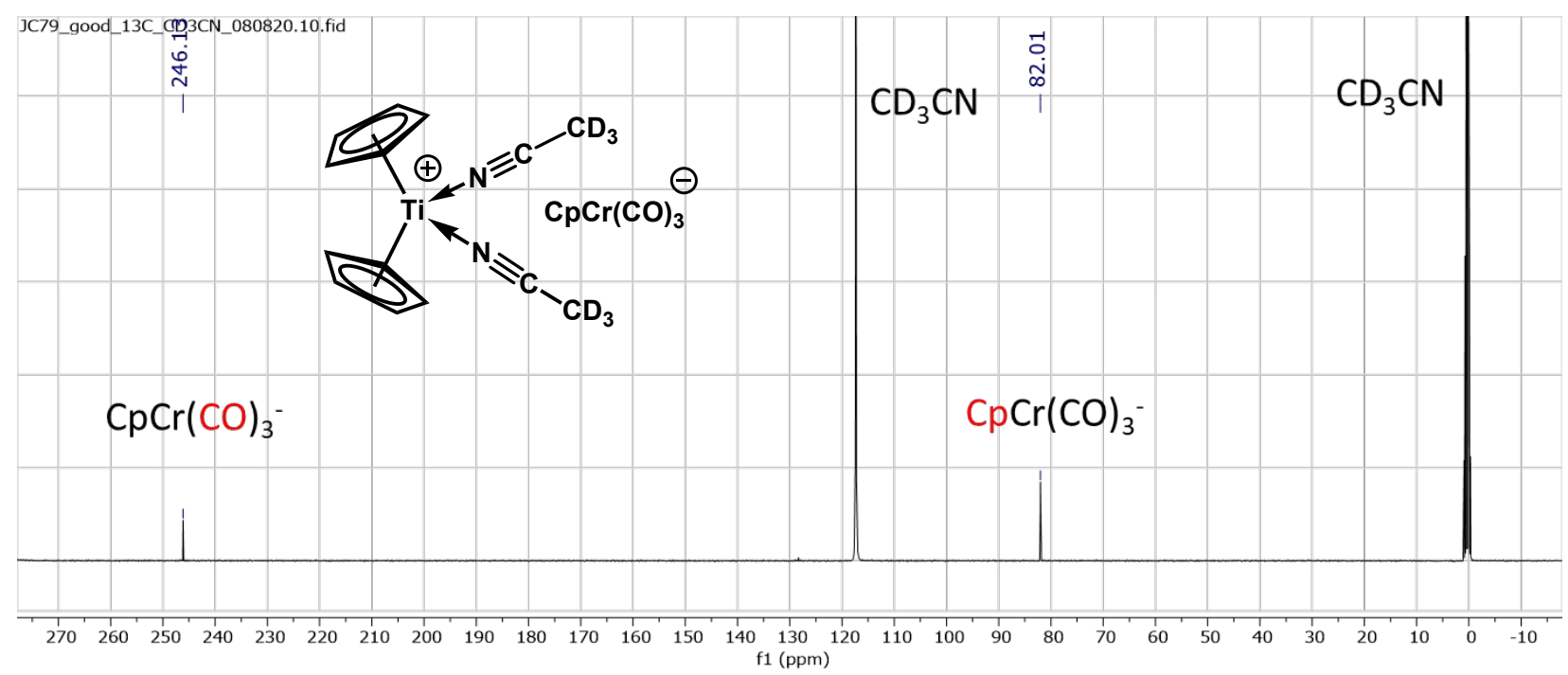

Figure S3. ${ }^{13} \mathrm{C}$ NMR $\left(\mathrm{CD}_{3} \mathrm{CN}\right)$ spectrum of $\mathbf{1}$.

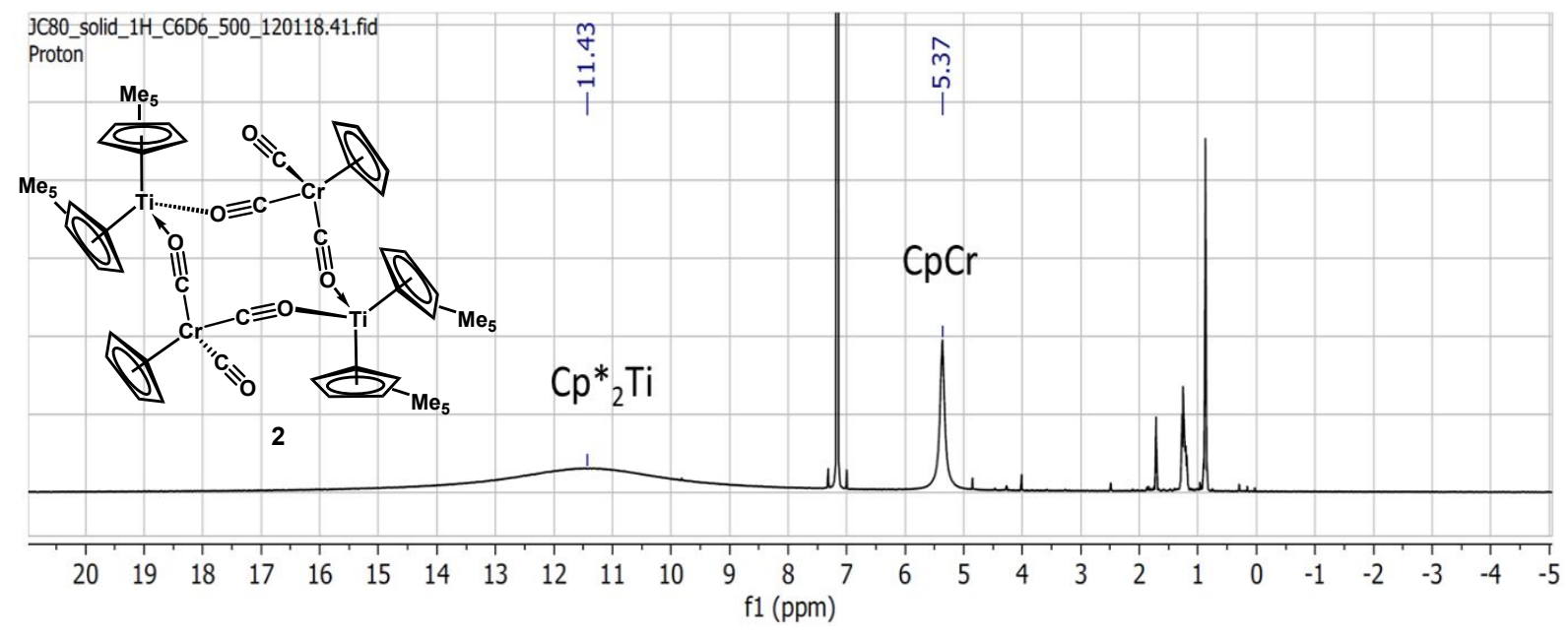

Figure S4. ${ }^{1} \mathrm{H}$ NMR $\left(\mathrm{C}_{6} \mathrm{D}_{6}\right)$ spectrum of 2. 


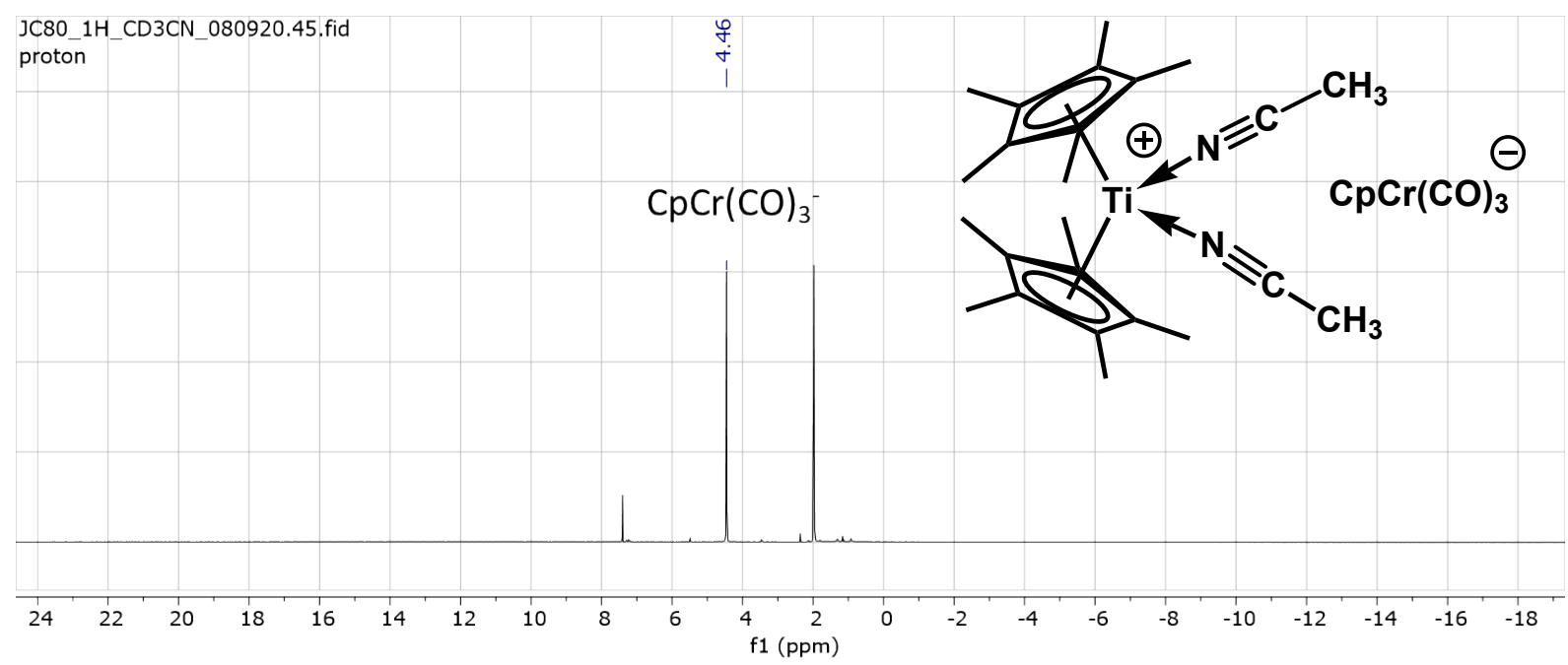

Figure S5. ${ }^{1} \mathrm{H}$ NMR $\left(\mathrm{CD}_{3} \mathrm{CN}\right)$ spectrum of 2.

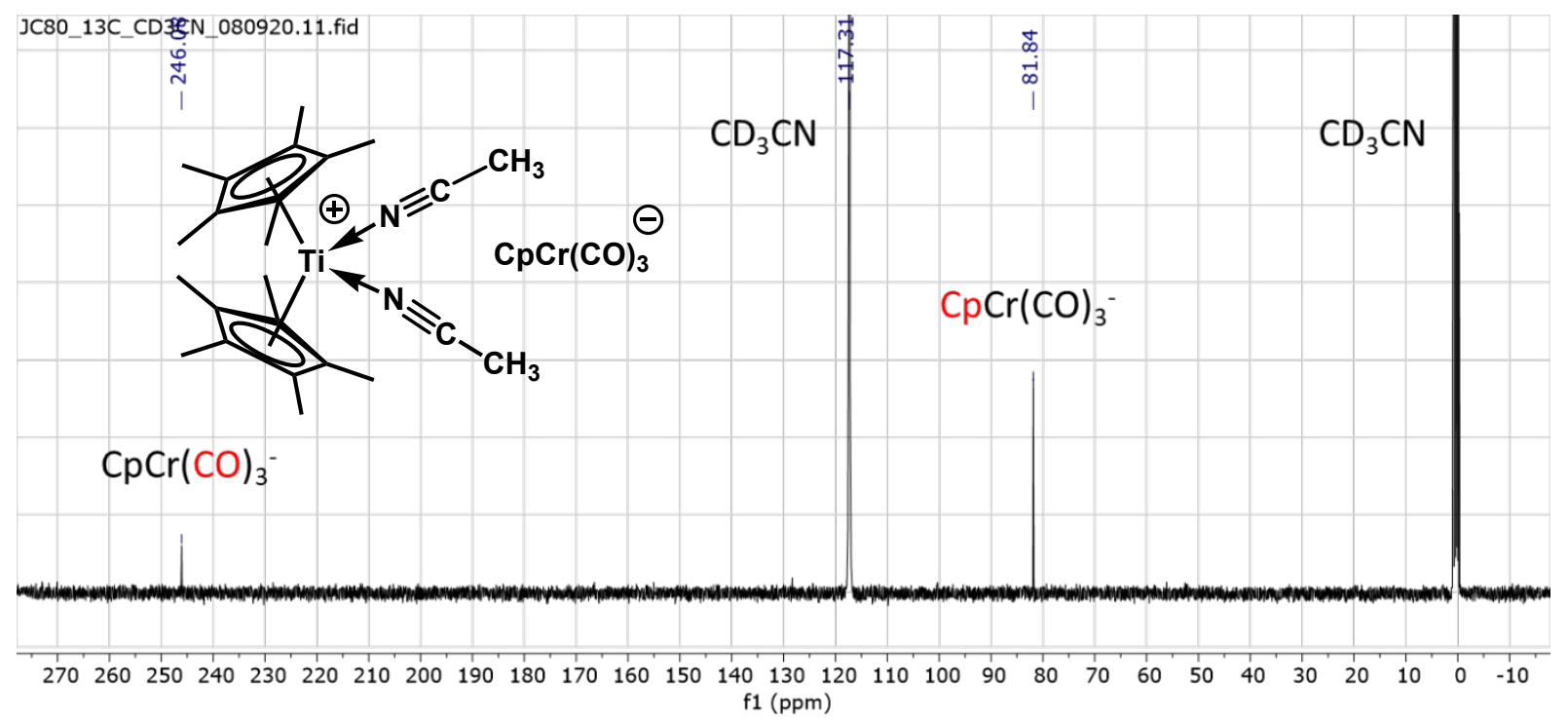

Figure S6. ${ }^{13} \mathrm{C} \mathrm{NMR}\left(\mathrm{CD}_{3} \mathrm{CN}\right)$ spectrum of 2 . 


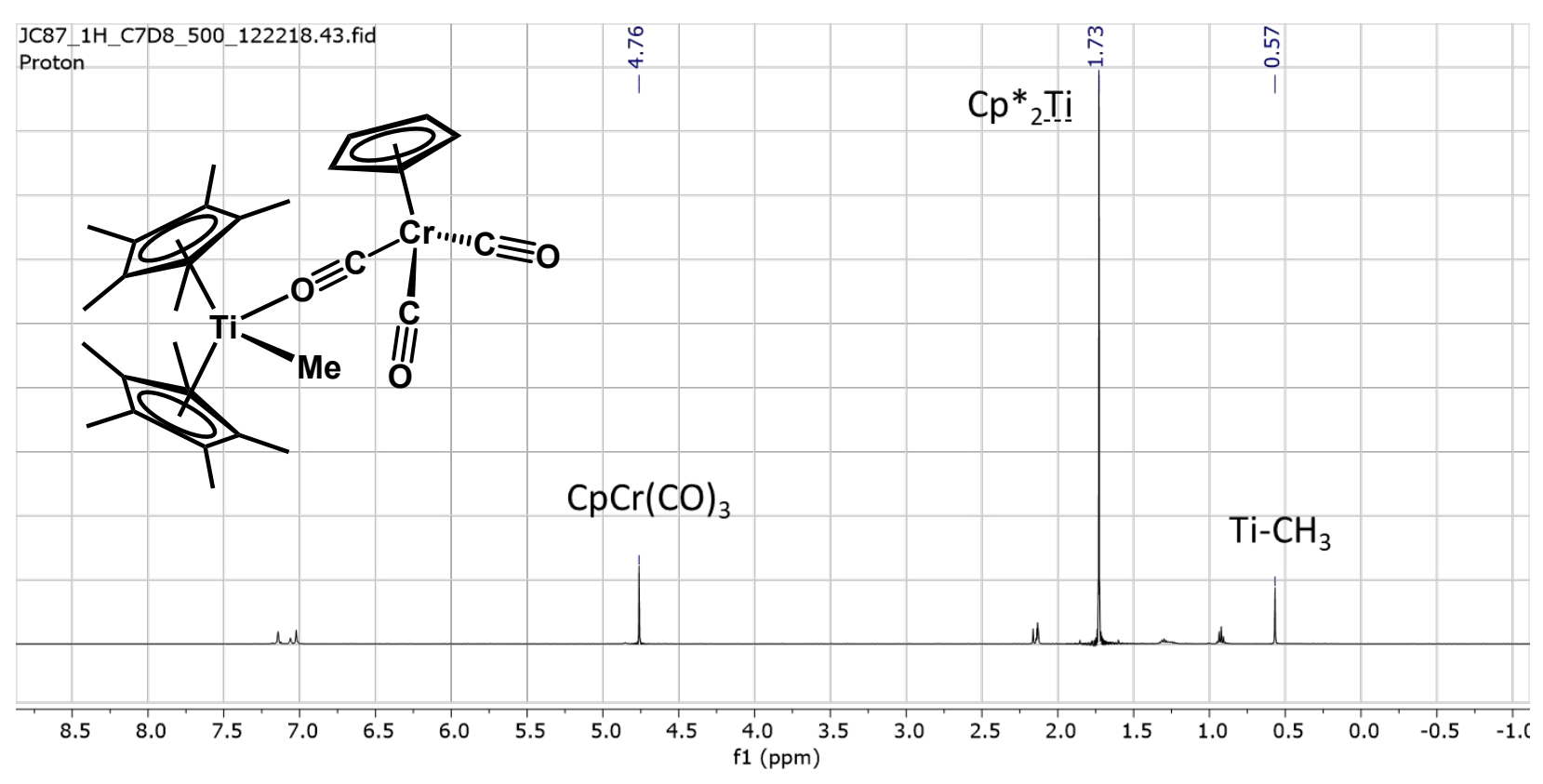

Figure S7. ${ }^{1} \mathrm{H}$ NMR $\left(\mathrm{C}_{7} \mathrm{D}_{8}\right)$ spectrum of $\mathbf{3}$.

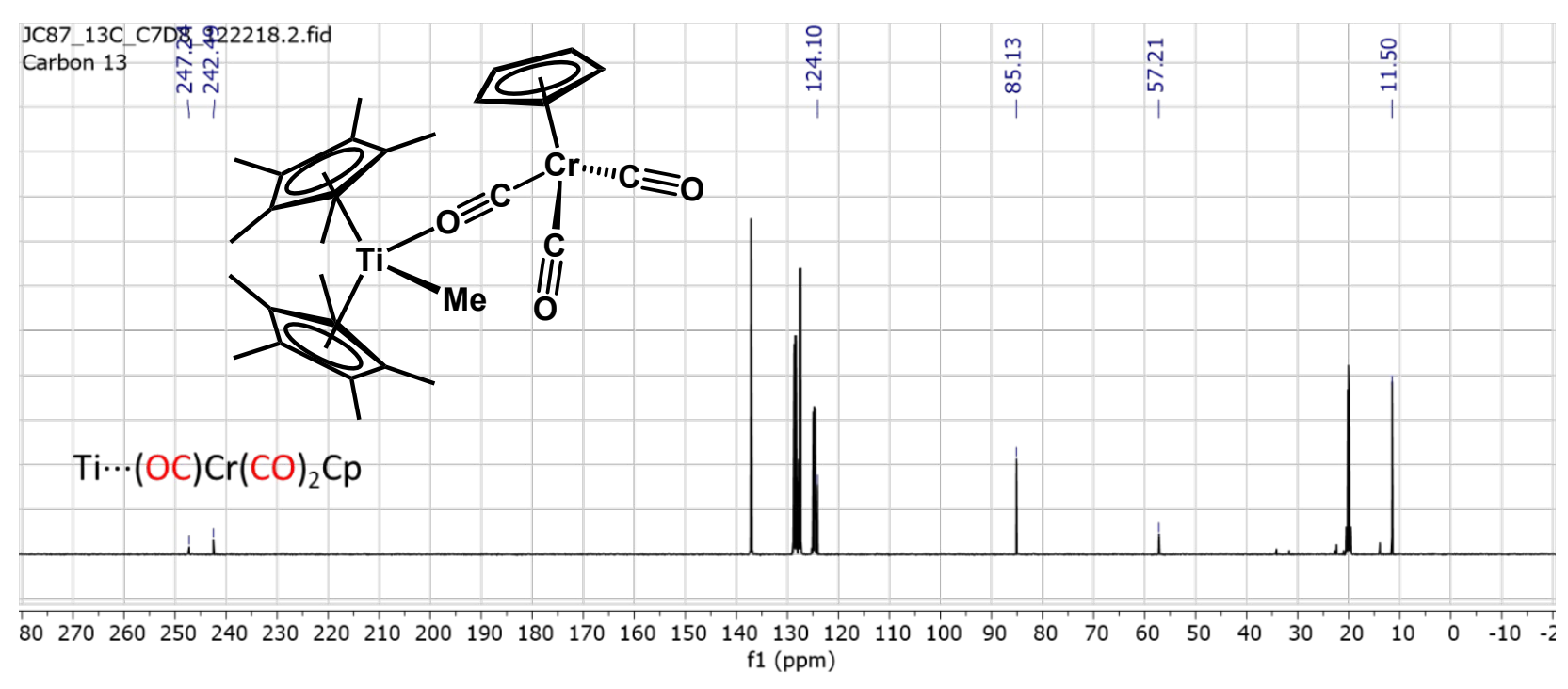

Figure S8. ${ }^{13} \mathrm{C}$ NMR $\left(\mathrm{C}_{7} \mathrm{D}_{8}\right)$ spectrum of 3 . 


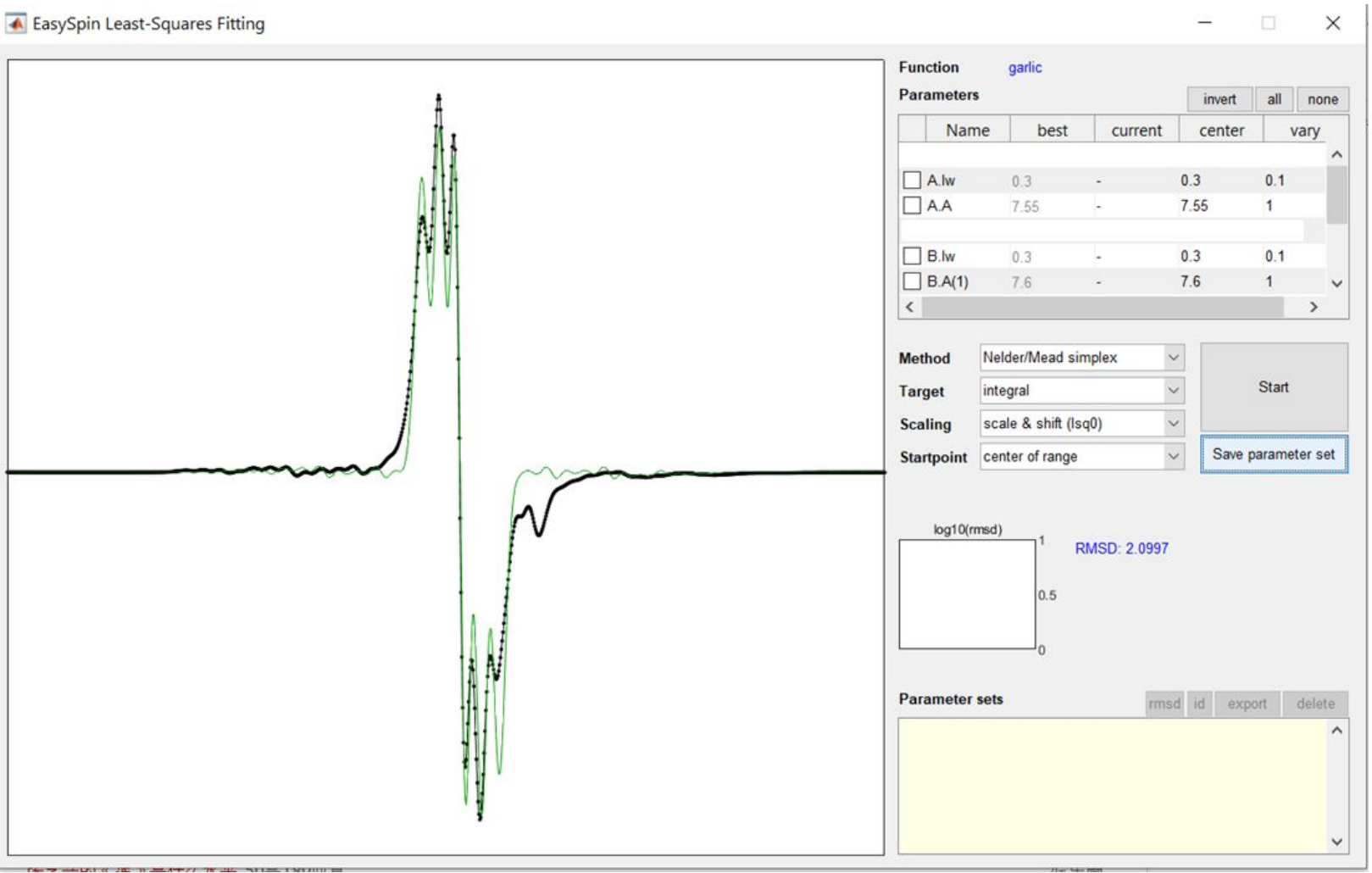

Figure S9. EPR spectrum of 2 recorded at room temperature in $\mathrm{CH}_{3} \mathrm{CN} / \mathrm{C}_{6} \mathrm{D}_{6}$ solution (microwave frequency $=9.746 \mathrm{GHz}$, sweep width $=150 \mathrm{G}) . \mathrm{g}_{\text {iso }}=1.983, \mathrm{~A}_{\text {iso }}\left({ }^{47} \mathrm{Ti}, \mathrm{I}=5 / 2\right.$, $\left.7.4 \% ;{ }^{49} \mathrm{Ti}, \mathrm{I}=7 / 2,5.4 \%\right)=27 \mathrm{MHz}, \mathrm{A}_{\text {iso }}\left(\right.$ two $\left.{ }^{14} \mathrm{~N}, \mathrm{I}=1,99.6 \%\right)=7.7 \mathrm{MHz}$.

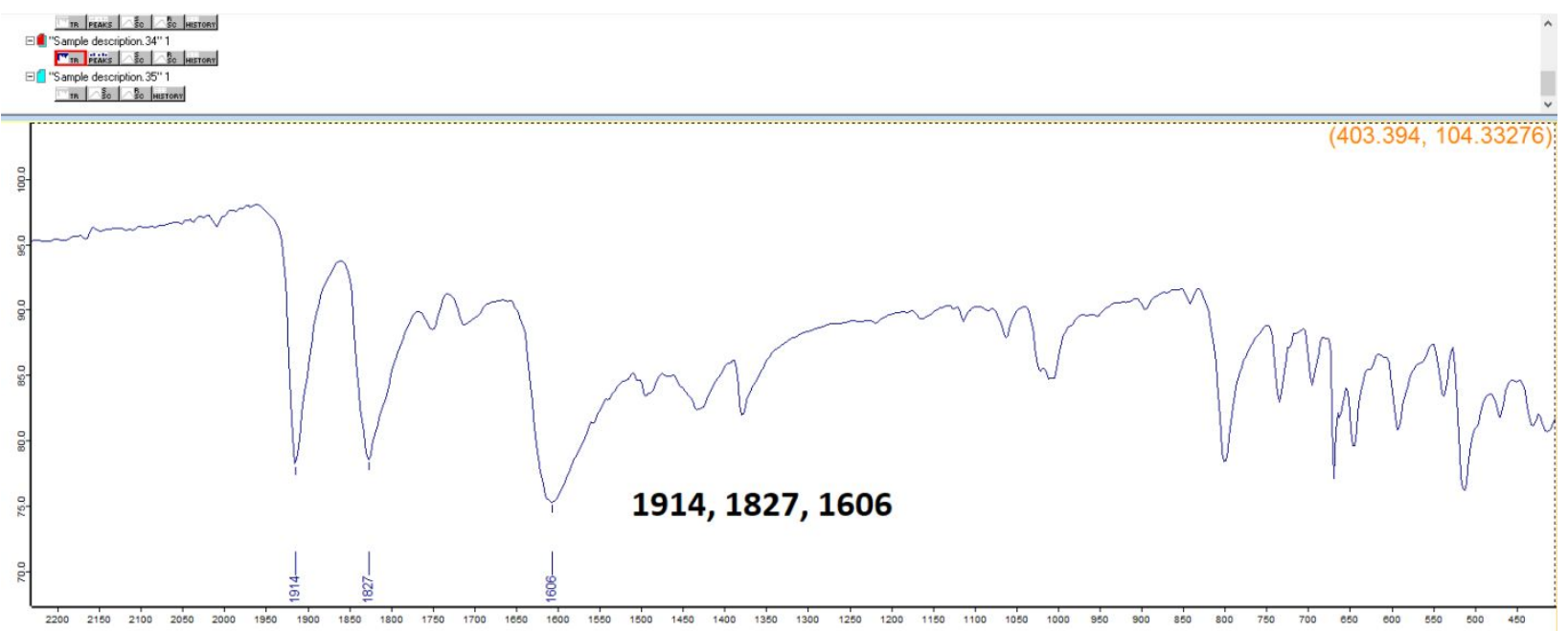

Figure S10. ATR-FTIR of $\left[\mathrm{Cp}_{2} \mathrm{Ti} \cdots(\mathrm{OC}) \mathrm{Cr}(\mathrm{CO})_{2} \mathrm{Cp}\right]_{2}(1)$ : 


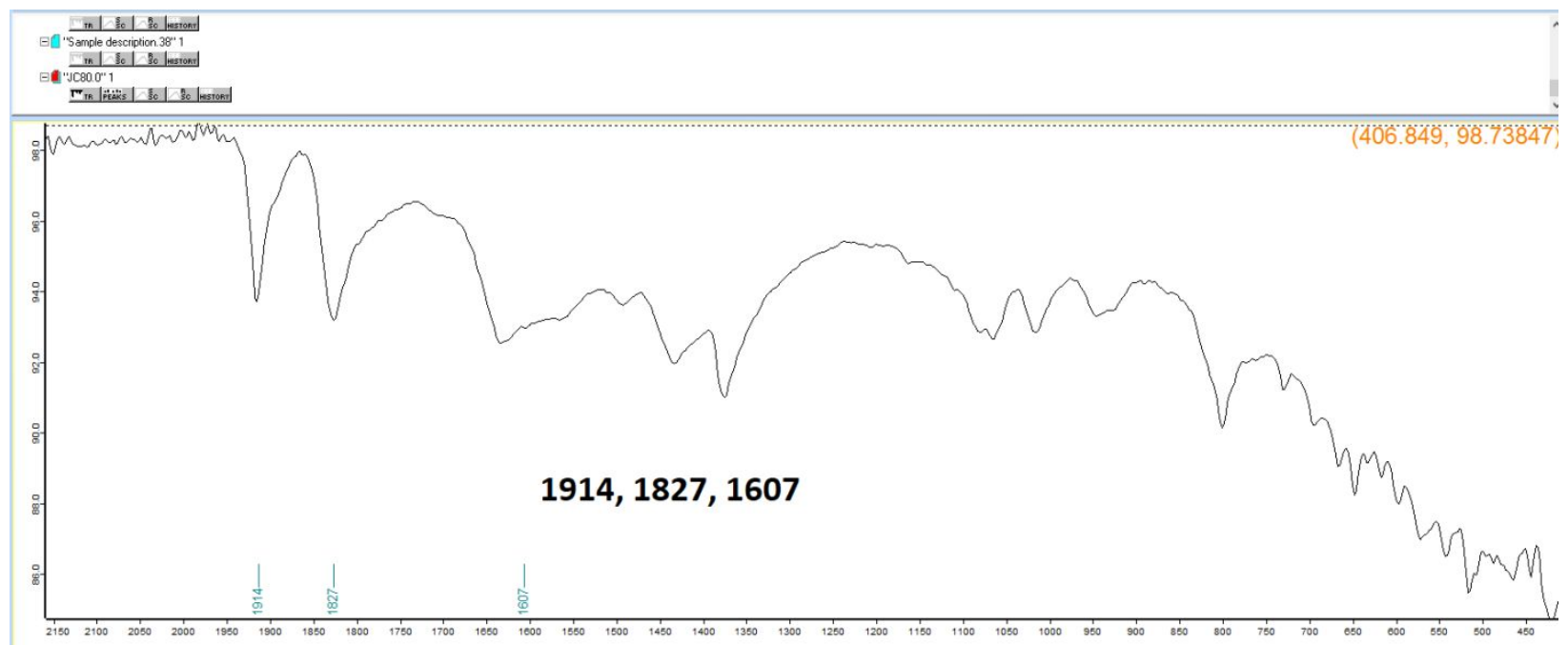

Figure S11. ATR-FTIR of $\left[\mathrm{Cp}_{2}{ }_{2} \mathrm{Ti} \cdots(\mathrm{OC}) \mathrm{Cr}(\mathrm{CO})_{2} \mathrm{Cp}\right]_{2}(2)$ :

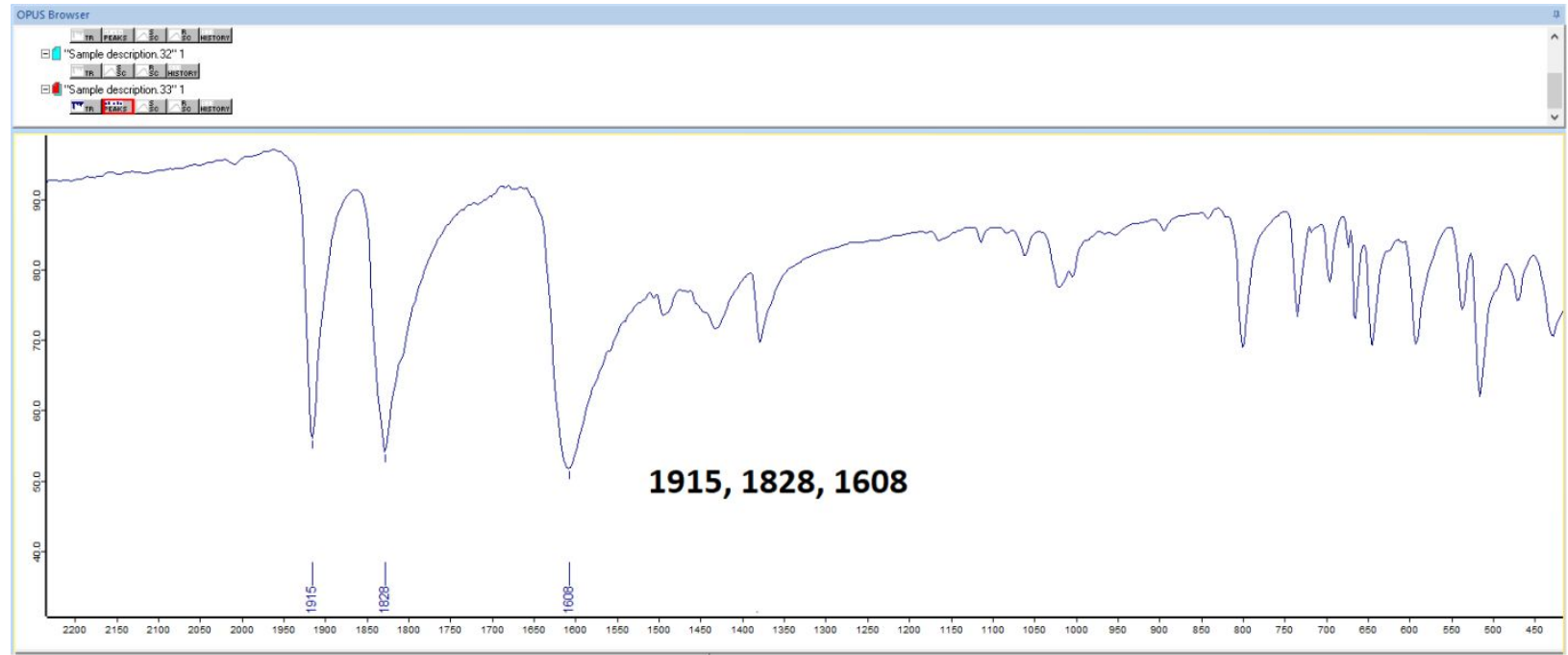

Figure S12. ATR-FTIR of $\mathrm{Cp}^{*}{ }_{2} \mathrm{Ti}\left(\mathrm{CH}_{3}\right) \cdots(\mathrm{OC}) \mathrm{Cr}(\mathrm{CO})_{2} \mathrm{Cp}_{2}$ (3): 


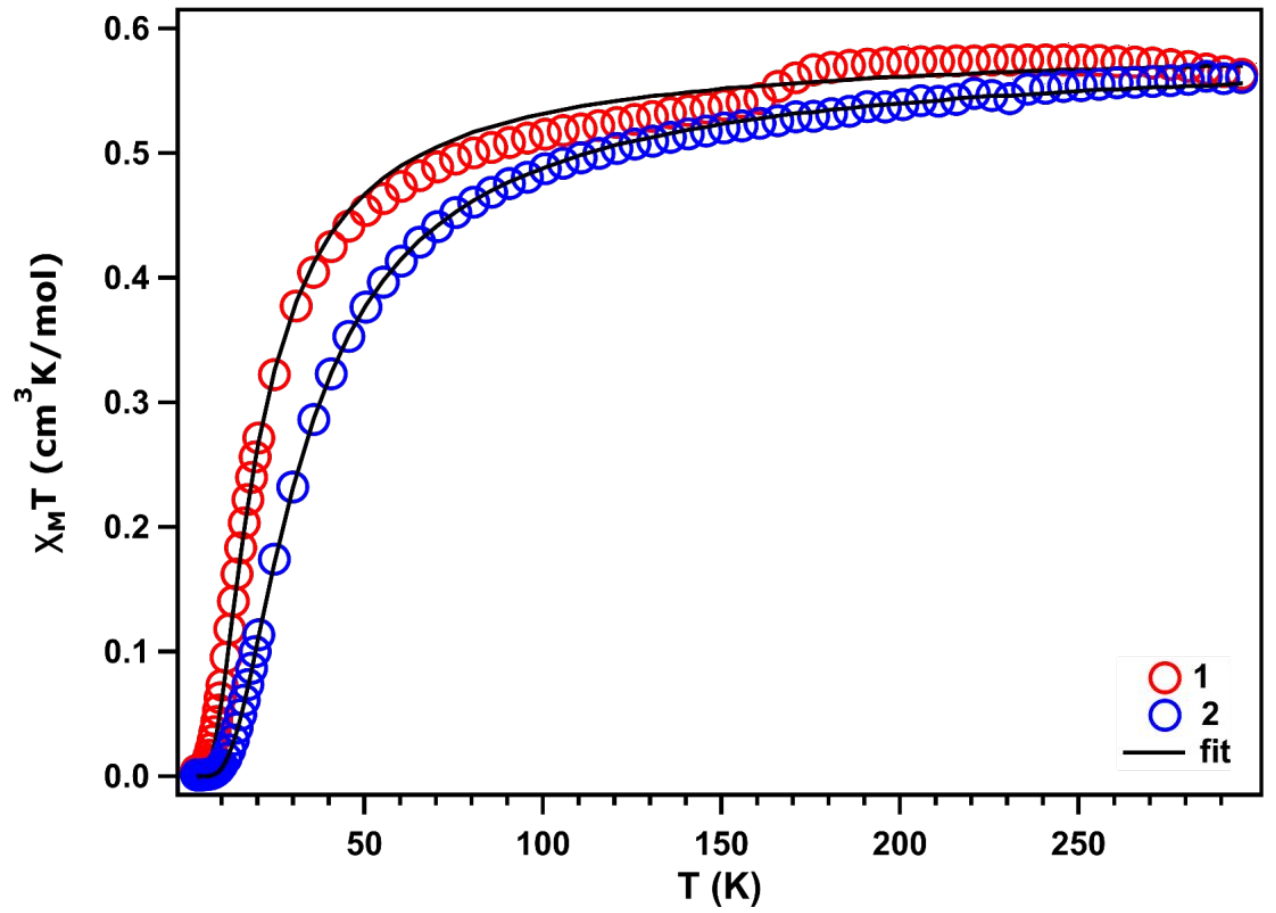

Figure S13. Variable-temperature magnetic susceptibility of $\mathbf{1}$ (red) and $\mathbf{2}$ (blue) with fit shown in solid black. For both $\mathbf{1}$ and $\mathbf{2}$ the fit corresponds to an antiferromagnetically coupled system with $\mathrm{S}_{\mathrm{A}}=\mathrm{S}_{\mathrm{B}}=1 / 2, \mathrm{~g}_{\mathrm{A}}=\mathrm{g}_{\mathrm{B}}=1.77$. For $1, \mathrm{~J}_{\mathrm{AB}}=-12.4 \mathrm{~cm}^{-1}$, for 2 , For $1, \mathrm{~J}_{\mathrm{AB}}=-20.4 \mathrm{~cm}^{-1}$.

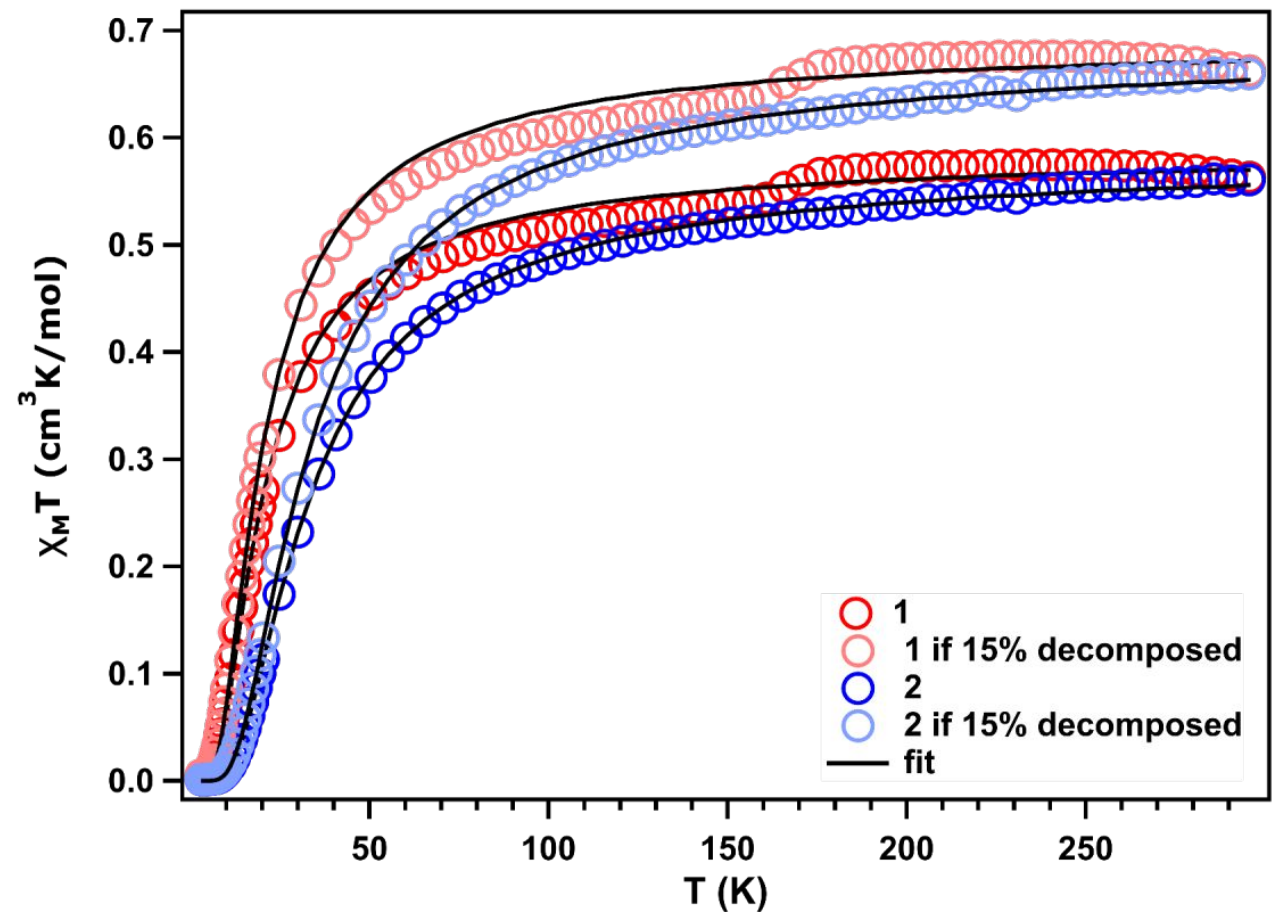

Figure S14. Variable-temperature magnetic susceptibility of $\mathbf{1}$ (red) and $\mathbf{2}$ (blue) and assuming that each sample was $15 \%$ decomposed to a diamagnetic material for $\mathbf{1}$ (pale red) and $\mathbf{2}$ (pale blue) with fit shown in solid black. For both $\mathbf{1}$ and $\mathbf{2}$ the fit for the possible decomposition scenario corresponds to an antiferromagnetically coupled system with $\mathrm{S}_{\mathrm{A}}=\mathrm{S}_{\mathrm{B}}=1 / 2, \mathrm{~g}_{\mathrm{A}}=\mathrm{g}_{\mathrm{B}}=1.92$ with $\mathrm{J}_{\mathrm{AB}}$ for $\mathbf{1}=-12.4 \mathrm{~cm}^{-1}$, and $\mathrm{J}_{\mathrm{AB}}$ for $\mathbf{2}=-20.4 \mathrm{~cm}^{-1}$. 
Table S1. Crystal, intensity, collection, and refinement data.

\begin{tabular}{|c|c|c|c|}
\hline & & 2 & 3 \\
\hline lattice & Triclinic & Monoclinic & Monoclinic \\
\hline formula & $\mathrm{C}_{36} \mathrm{H}_{30} \mathrm{Cr}_{2} \mathrm{O}_{6} \mathrm{Ti}_{2}$ & $\mathrm{C}_{56} \mathrm{H}_{70} \mathrm{Cr}_{2} \mathrm{O}_{6} \mathrm{Ti}_{2}$ & $2\left(\mathrm{C}_{29} \mathrm{H}_{38} \mathrm{CrO}_{3} \mathrm{Ti}\right)\left(\mathrm{C}_{7} \mathrm{H}_{8}\right)$ \\
\hline formula weight & 758.40 & 1038.92 & 1161.12 \\
\hline space group & $P 2_{l} / n$ & $P 2_{1} / n$ & $P 2_{1} / n$ \\
\hline$a / \AA$ & $12.0020(13)$ & $10.6484(10)$ & $9.9464(6)$ \\
\hline$b / \AA$ & $10.4582(11)$ & $13.2625(12)$ & $18.7250(11)$ \\
\hline$c / \AA$ & $13.5609(14)$ & 18.751618) & $15.9979(9)$ \\
\hline$\alpha /^{\circ}$ & 90 & 90 & 90 \\
\hline$\beta /^{\circ}$ & $111.4319(15)$ & $102.0056(15)$ & $101.1335(9)$ \\
\hline$\gamma^{\circ}$ & 90 & 90 & 90 \\
\hline$V / \AA^{3}$ & $1584.5(3)$ & $2590.3(4)$ & $2923.5(3)$ \\
\hline$Z$ & 2 & 2 & 2 \\
\hline temperature $(\mathrm{K})$ & $210(2)$ & $180(2)$ & $210(2)$ \\
\hline radiation $(\lambda, \AA)$ & 0.71073 & 0.71073 & 0.71073 \\
\hline$\rho$ (calcd.) $\mathrm{g} \mathrm{cm}^{-3}$ & 1.590 & 1.332 & 1.319 \\
\hline$\mu(\mathrm{Mo} \mathrm{K} \alpha), \mathrm{mm}^{-1}$ & 1.20 & 0.75 & 0.68 \\
\hline$\theta$ max, deg. & 30.4 & 30.6 & 30.5 \\
\hline no. of data collected & 18564 & 31512 & 47075 \\
\hline no. of data & 7613 & 7960 & 8917 \\
\hline no. of parameters & 208 & 308 & 370 \\
\hline$R_{I}[I>2 \sigma(I)]$ & 0.0472 & 0.0495 & 0.0413 \\
\hline$w R_{2}[I>2 \sigma(I)]$ & 0.1170 & 0.0978 & 0.1067 \\
\hline$R_{I}$ [all data $]$ & 0.0640 & 0.0980 & 0.0621 \\
\hline$w R_{2}$ [all data] & 0.1288 & 0.1165 & 0.1206 \\
\hline GOF & 1.06 & 1.012 & 1.038 \\
\hline$R_{\text {int }}$ & 0.109 & 0.083 & 0.038 \\
\hline
\end{tabular}




\section{Computational Methods.}

General Procedures. DFT calculations were performed with Gaussian 16. Geometries were optimized without symmetry constraints. No imaginary frequencies were observed in subsequent vibrational calculations confirming that structures reside at potential-surface minima. Calculations employed the B3LYP functional the $6-311+\mathrm{G}^{*}$ basis set for atoms $\mathrm{H}$ through $\mathrm{Cl}$ and the LANL2DZ basis set and effective core potentials for $\mathrm{Cr}$ and Ti. Compound 1-M was modeled as a spin doublet and Compound 1 was modeled as a spin triplet. Convergence criteria for optimization were ("tight" keyword) $1.0 \times 10^{-5}$ (RMS force threshold), $1.5 \times 10^{-5}$ (Maximum force threshold), $4.0 \times 10^{-5}$ (RMS displacement threshold), $6.0 \times 10^{-5}$ (Maximum displacement threshold) in atomic units. The integration grid consisted of 99 radial shells with 590 angular points ("ultrafine" keyword).

The supplemental file "DFT_Compounds" contains the computed Cartesian coordinates of all of the molecules reported in this study. The file may be opened as a text file to read the coordinates, or opened directly by a molecular modeling program such as Mercury (version 3.3 or later, http://www.ccdc.cam.ac.uk/pages/Home.aspx) for visualization and analysis.

Table S2. Thermally Corrected Free Energies for $\mathrm{H}_{2}, \mathbf{1}-\mathbf{H}, \mathbf{1 - M}$, and 1 (Ha.)

\begin{tabular}{lll}
\hline Compound & SCF Energy & $\mathrm{G}$ \\
\hline $\mathrm{H}_{2}$ & -1.176631 & -1.178107 \\
$\mathbf{1 - H}$ & -1065.907654 & -1065.678195 \\
$\mathbf{1 - M}$ & -1065.328583 & -1065.108574 \\
$\mathbf{1}$ & -2130.689914 & -2130.223497 \\
\hline
\end{tabular}

\section{References:}

1. Chilton, N. F.; Anderson, R. P.; Turner, L. D.; Soncini, A.; Murray, K. S. PHI: A Powerful New Program for the Analysis of Anisotropic Monomeric and Exchange-Coupled Polynuclear d- and f-Block Complexes. J. Comput. Chem. 2013, 34, 1164-1175.

2. Sheldrick, G. M., SHELXTL, An Intergrated System for Solving, Refining, and Displaying Crystal Structures from Diffraction Data. University of Göttingen, Göttingen, Federal Republic of Germany, 1981.

3. Sheldrick, G. M. A Short History of SHELX. Acta Crystallogr., Sect. A: Found. Crystallogr. 2008, 64, 112-122.

4. Sheldrick, G. M. Crystal structure refinement with SHELXL. Acta Crystallogr., Sect. C: Struct. Chem. 2015, 71, 3-8.

5. Pangborn, A. B.; Giardello, M. A.; Grubbs, R. H.; Rosen, R. K.; Timmers, F. J. Safe and Convenient Procedure for Solvent Purification. Organometallics 1996, 15, 1518-1520.

6. Rosenthal, U.; Burlakov, V. V.; Arndt, P.; Baumann, W.; Spannenberg, A. The Titanocene Complex of Bis(trimethylsilyl)acetylene: Synthesis, Structure, and Chemistry. Organometallics 2003, 22, 884-900.

7. Burlakov, V. V.; Rosenthal, U.; Beckhaus, R.; Polyakov, A. V.; Struchkov, Y. T.; Oehme, G.; Shur, V. B.; Volpin, M. E. New Alkyne Complexes of Titanocene and Permethyltitanocene without Additional Ligands. The First X-ray Diffraction Study of an Alkyne Complex of This Type. Organomet. Chem. USSR 1990, 3, 237-238. 
8. Bercaw, J. E.; Bell, L. G.; Brintzin.Hh; Marvich, R. H. Titanocene as an Intermediate in Reactions Involving Molecular-Hydrogen and Nitrogen. J. Am. Chem. Soc. 1972, 94, 1219-1238. 9. Jordan, R. F.; Norton, J. R. Kinetic and Thermodynamic Acidity of Hydrido TransitionMetal Complexes. 1. Periodic Trends in Group-6 Complexes and Substituent Effects in Osmium Complexes. J. Am. Chem. Soc. 1982, 104, 1255-1263.

10. Keppie, S. A.; Lappert, M. F. Binuclear Organometallic Compounds. 5. Insertion into M$\mathrm{C}$ and $\mathrm{H}-\mathrm{C}$ Bonds of Coordinatively Unsaturated Transition-Metal Fragments - Synthesis of Group-VIA Metal Cyclopentadienyltricarbonyl Metallates (Germanium and Tin) and Hydrides. J. Chem. Soc. A 1971, 3216-3220.

11. Keppie, S. A.; Lappert, M. F. Insertion into Metal-Carbon and Hydrogen-Carbon Bonds Synthesis of Group VIA Metal Cyclopentadienylcarbonyl Metallates and Hydrides. $J$. Organomet. Chem. 1969, 19, P5-P6.

12. King, R. B.; Stone, F. G. A. Cyclopentadienyl Metal Carbonyls and Some Derivatives. Inorg. Syn. 1963, 7, 99-115. 